\section{DRIVING PATIENTS INTO YOUR PRACTICE}

Denplan has launched a new initiative to use its unique consumer-facing brand to help drive patients into member practices - this time through the launch of the Denplan Discount Network.

The Denplan Discount Network is designed to provide Denplan practices with access to the 200,000 employees currently covered by its corporate benefit products by offering them special discounted rates.

So far, 1,500 Denplan dentists have joined the network and this number is growing every day. It works because Denplan is able to provide employers with information about the service and actively work with them to ensure their employees are aware of all the participating dentists in their area. All of this is available to the employee though a secure, easy to use website complete with Google Maps, showing the participating dentists local to them and the level of discount offered.

New patients contacting dentists as a result of the network simply present themselves as a private fee-peritem patient and the discount offered is then deducted from the price of their private treatment by the practice. The employee pays the practice as normal, as they claim back their benefit entitlement directly from Denplan.

If you are a Denplan member and wish to join the Network, please call 08001699962.

\section{STAY IN THE DRIVING SEAT OF YOUR BUSINESS}

Stay in the driving seat of your business with Back Office from Carestream Dental. The easy-touse business management tools enable you to monitor practice performance so that you can make those all-important decisions to maximise productivity and income potential.

Designed specifically for dental practices, Back Office caters to your every need for sound practice management and helps you to achieve CQC compliance. The software module covers the following key areas: Payroll; Purchase Ledger; Nominal Ledger; Bank Account Management; Stock Control; Petty Cash; and Staff Records.

Back Office also facilitates the generation of comprehensive staff records, demonstrating adherence to CQC outcomes relating to workers. Information includes training, personal development and performance reviews, in addition to holiday time and absenteeism.

offering a range of personalised reports, Back Office offers you the clearest possible picture of your business, allowing you to identify any areas for improvement and deal with it accordingly. For a better business, choose Back Office.

For more information, contact Carestream Dental on 08001699692 or visit www. carestreamdental.co.uk.

\section{CHOOSE YOUR NEW PRACTICE ONLINE}

Tavom UK has long been recognised as a leading international manufacturer of dental, veterinary and medical cabinetry, and now all products can be viewed from their new website www.tavomuk.com.

The experts at Tavom UK will help you plan your new practice layout, ensuring the design is tailored to your individual needs and requirements. Effective ergonomics, easy-to-clean designs and quality materials allow for an efficient workflow, while meeting HTM 01-05 regulations.

You can then choose which cabinetry style and colour you prefer from an extensive product range, with a full PDF catalogue available to download online. Unlike wooden cabinetry suppliers, Tavom furniture is built off-site, reducing dust and disruption and eliminating the need for expensive labour charges. Tavom cabinetry is precision made and delivered to your door ready to be placed in position and levelled with adjustable feet.

To see how Tavom UK can transform your practice, visit the new website www.tavomuk. com, or call 08707521121.

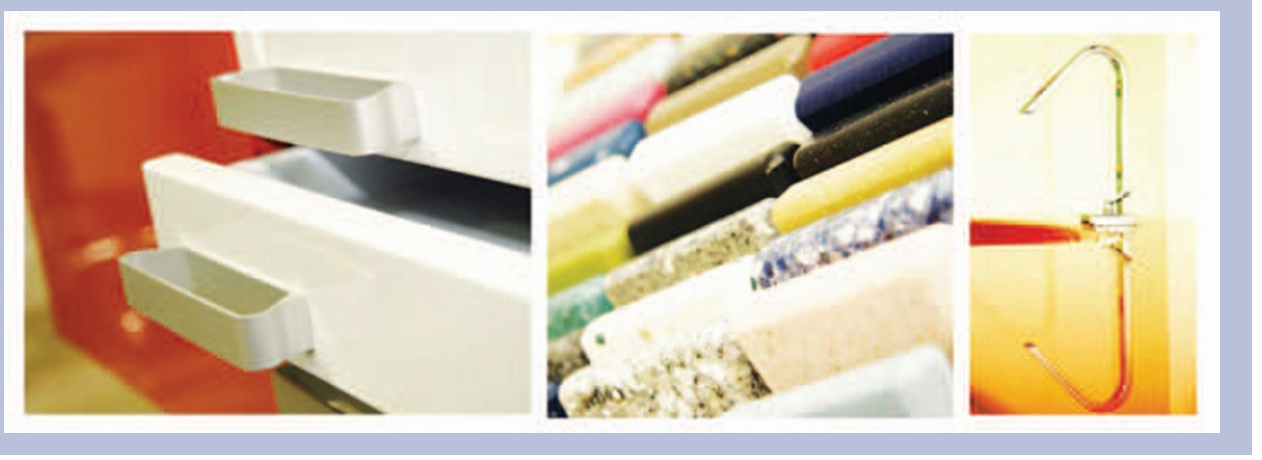

\title{
ACHIEVE VISIBLE RELIEF FROM XEROSTOMIA
}

Not-for-profit organisation The

Dry Mouth Foundation offers the Niemtzow Dry Mouth protocol and also trains new practitioners from the acupuncture and dental professions.

The Niemtzow Dry Mouth protocol is a point precise acupuncture protocol to treat radiotherapy-induced xerostomia for cancer patients, created by Dr Richard Niemtzow, a colonel in the US Air Force.
Dental professionals are ideally placed to both identify xerostomia and, with appropriate training, offer patients treatment for improved oral hygiene following radiotherapy or Sjögren's syndromeinduced xerostomia. The results are improved oral cavity hygiene, elimination of harmful gels and sprays, and physiological benefits for the patient.

Patients receiving the point precise needle sequence have shown visible results within 15 minutes of the first of two treatment sessions, producing significant saliva flow for several months or years. For further information visit http:// drymouthfoundation.org. 